\title{
4 The human factor - garbage pickers
}

In most urban areas, municipal departments are responsible for the disposal of solid waste. This waste is taken out of the city and transported to landfills or incinerator facilities. However, in reality, long before this garbage is disappeared completely, it is painstakingly - but not completely - sorted to remove anything that might be of value: metals, glass, plastics, paper, cardboard, textiles, aluminium, lead, steel, etc. The informal and unregulated practice of hand-sorting waste has a long history in urban China's pre-modern times and has continued into the present. It has become an important way to reduce the size of the waste stream and has provided the huge amounts of recycled resources and raw materials that industrial production needs. They have also reduced manufacturing and environmental costs of production considerably, as virgin resources do not need to be prospected, mined, and produced. Nowadays, the people who are sorting through the garbage of others belong to the groups of migrant workers who have moved from the countryside in waves since the $1980 \mathrm{~s}$ to try to make a living and to become part of the city. They have effectively tried to escape the drudgery and lack of perspective of the countryside, to have more economic and life opportunities, to be recognized as full members of Chinese society and, at some stage, to even become registered as city dwellers - thereby gaining access to the many benefits that urbanites enjoy.

\section{Migrant labourers}

Who takes care of the waste of daily life in Beijing, apart from the workers employed by the municipal sanitation department? Who are these people sorting through other people's waste? The decollectivization of agriculture and the reduced control over the rural population in the 1980 s - the result of a less strict implementation of the hukou legislation that tied people to their native areas - caused a vast pattern of migration to emerge, at one point making up more than 20 percent of the population (Wong, Li, and Song, 2007; Steuer et al., 2017). Some 100 to 200 million people are estimated to have left their rural homes since the 1980s (Solinger, 2006: 179). Decollectivization made superfluous labour power in the countryside both visible and problematic, as rural incomes became directly related to labour input. The large groups of underemployed labourers that had existed in the countryside could no longer find work, and families found the burden of supporting underperforming kin increasingly unbearable. During slow periods of farm work, peasants 
first made the move to urban areas, starting with the nearest townships and ending in the big cities and newly established industrial boomtowns along the Eastern Seaboard, such as Shenzhen. They found work in the urban building industry, which had an insatiable appetite for labour. Others were employed in the assemblage and piece-work production modes that thrived in the many new factories and workshops set up by foreign-owned, Hong Kong, and Taiwanese companies. After a short time, this migration pattern ceased to be seasonal and peasants started to move east and stay for good. The mechanism of chain migration enabled many people to move away from the land (Solinger, 1999). This itinerant labour power increasingly ended up in the metropolises, i.e., Beijing, Shanghai, Guangzhou, and others; in a later stage, second-tier cities such as the provincial capitals also became favoured destinations. Most labour migrants found employment doing casual or unschooled labour. This was not necessarily by choice, however: many cities barred migrants from a number of job categories (Béja et al., 1999a, 1999b; Zhang, 2002; Liu, Wong, and Liu, 2013).

This growth of rural-urban migration was linked closely to the spectacular demand for construction workers in urban areas where the scarcity of adequate living facilities increasingly felt like a burden (Guang, 2005). Agricultural labourers were seen as compliant, sturdy, and dependable workers, who were thus well-suited for the demands of construction work (Goldstein, 2006; Mobrand, 2006). Many of the waste pickers that were interviewed for this project started out as members of rural construction teams in the $1990 \mathrm{~s}$ (Li, 2006; Interviews, 2017) before moving on to other occupations. They moved on either because cheaper labour power had replaced them, or because they calculated that waste picking offered better earning opportunities. By taking on work that most born-and-bred urbanites considered too dirty, too demeaning, and too poorly paid - even when these urbanites were themselves unemployed as result of lay-offs by their former employers, the state-owned enterprises (SOEs) - the migrant workers filled an essential niche in the urban configuration (Solinger, 2006; Goldstein, 2006). One can argue that the migrant labour force has functioned as a lubricant for China's growth.

\section{Waste picking}

The migrant worker-turned-scrap collector took over the work that was left when the formal recycling structure disappeared. In the process, they have developed collection patterns that are reminiscent of the routines followed by the 'pole carriers', 'big basket toters', 'small drum beaters', and 
Illustration 4.1 Collected PET bottles and assorted plastics waiting to be moved to the next higher collection point for further processing, Haidian

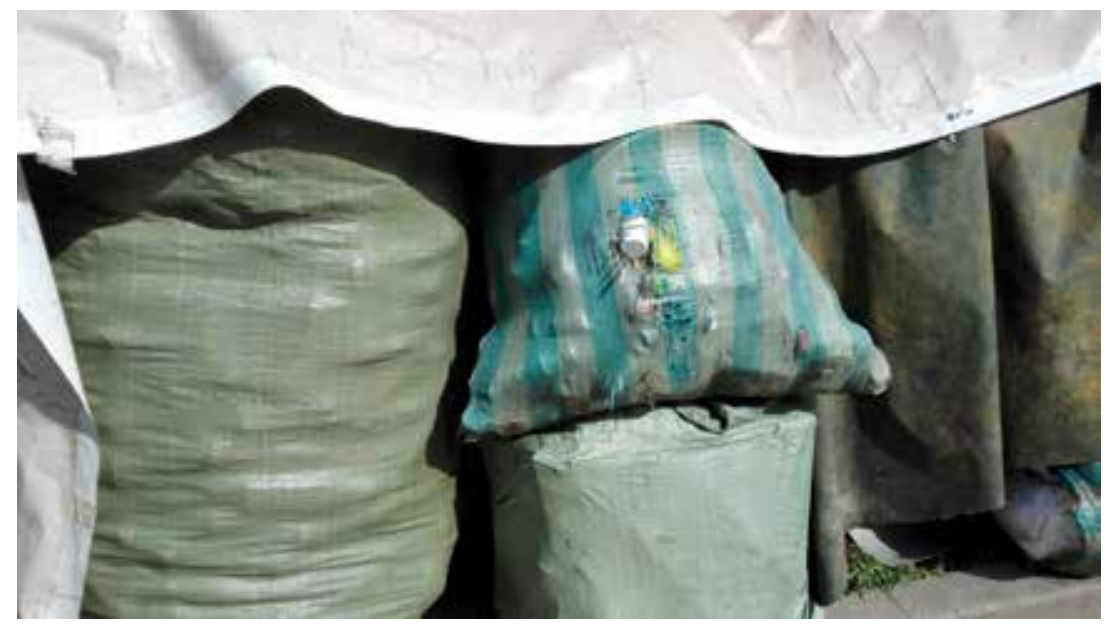

Author's photograph, April 2017

'large drum beaters' of the 1930s (Goldstein, 2006; Steuer et al., 2017). They collect, bring together, or buy recyclable materials that they then transport to transfer stations, where these materials are sold for a higher price; in the process they earn a reward, or wages, for their labour input. Migrant workers in transfer stations move the trash higher in the waste stream, until it finally arrives at the recycling companies that turn it into resources. It is hard and demanding work, consuming a lot of time, but even the small mark-ups earned by the sorting and transporting of waste can generate a total income that dwarfs the poor rewards that migrants still working in the construction sector hope to receive. It is irrelevant to compare waste picking with the income that can be received from rural work. Moreover, as my sources stressed time and again, their independent status is a major consideration for such migrants: one is free to do what one wants when one wants to do it, and there is nobody who can change that.

I agree with the observations of Wu and Zhang (2016), who reject the idea that these waste pickers are down and out, with no other job to turn to, and almost by default gravitate towards waste picking (Hunwick, 2015). People do not end up picking waste. Migrants do have agency and they are proud of the work they do (Interviews, 2017). As a result, garbage picking looks less like an earning opportunity of the last resort, and more like a way to get rich relatively quickly and independently. This line of thinking is further supported by the many stories making the rounds among migrant workers, 
which tell of waste pickers who became the 'King of Glass', the 'King of Plastics', even the 'King of Steel and Aluminium', earning billions of yuan in the Beijing suburbs in the days when the numbers of waste sorters were smaller and there was more waste to pick (China Youth News, 2016; Zhao, 2016). The legendary exploits of these pioneers of waste sorting provide motivation and inspiration to the migrant workers (Illustration 4.1).

Changing one's source of income is often possible because native-place ties offered a chance to move elsewhere. In conjunction with occupational networks, native-place networks are particularly relevant in the wastepicking business. Encountering people from the same village, district, town, or province who are engaged in more lucrative work, for example waste picking, opens up new and more rewarding opportunities to earn a living (Mobrand, 2006; Wu and Zhang, 2016). This network of native-place ties has also resulted in serious competition and fights between networks concerning choice spots and types of work, leading to (informal and intergroup) agreements about which group engages with which type of waste (Zhao, 2016).

Some of these choice spots are the government units that still run their own recycling operations. These danwei, such as universities and other types of work units, classify and separate their garbage themselves. The moving and disposing of the recyclables is then contracted out to small operators, i.e., waste pickers, while the non-recyclable garbage is hauled off by the district or municipal sanitation department (Ensmenger, Goldstein, and Mack, 2005; Fieldnotes, 2017). I had the opportunity to observe the practice in one such unit, Peking University in Haidian District, in some detail. All day long, employees of the University's own sanitation department collect the garbage and waste produced by the estimated 50,000 people living and working within the unit (Interviews, 2017). Aside from the household and kitchen garbage of the departments, dormitories, dining halls, restaurants, and waste bins, the yield also includes the green waste (branches, leaves, duckweed, grass clippings, etc.) that is left from the process of maintaining the vast grounds and lakes of the university. All this waste is collected at a central point in the Southwest corner of the campus and sorted in a non-systematic way: some, but not all, of the plastics, cans, paper and cardboard, textiles, etc., are taken out and kept aside in the yard behind the collecting station. What is left is compressed in an underground container that is depleted, but not emptied, twice a day by a garbage truck operated by the Haidian Sanitation and Environment Bureau. These trucks deliver their loads to two incinerator facilities, one in Liulitun and one in Dagongcun, Sujiatuo, both located in Haidian District. One of the truck drivers emphatically said that Haidian waste needs to be incinerated in Haidian, suggesting 
Illustration 4.2 Paper and cardboard at a Xiyuan Bridge collection point, Haidian, waiting to be moved for further processing

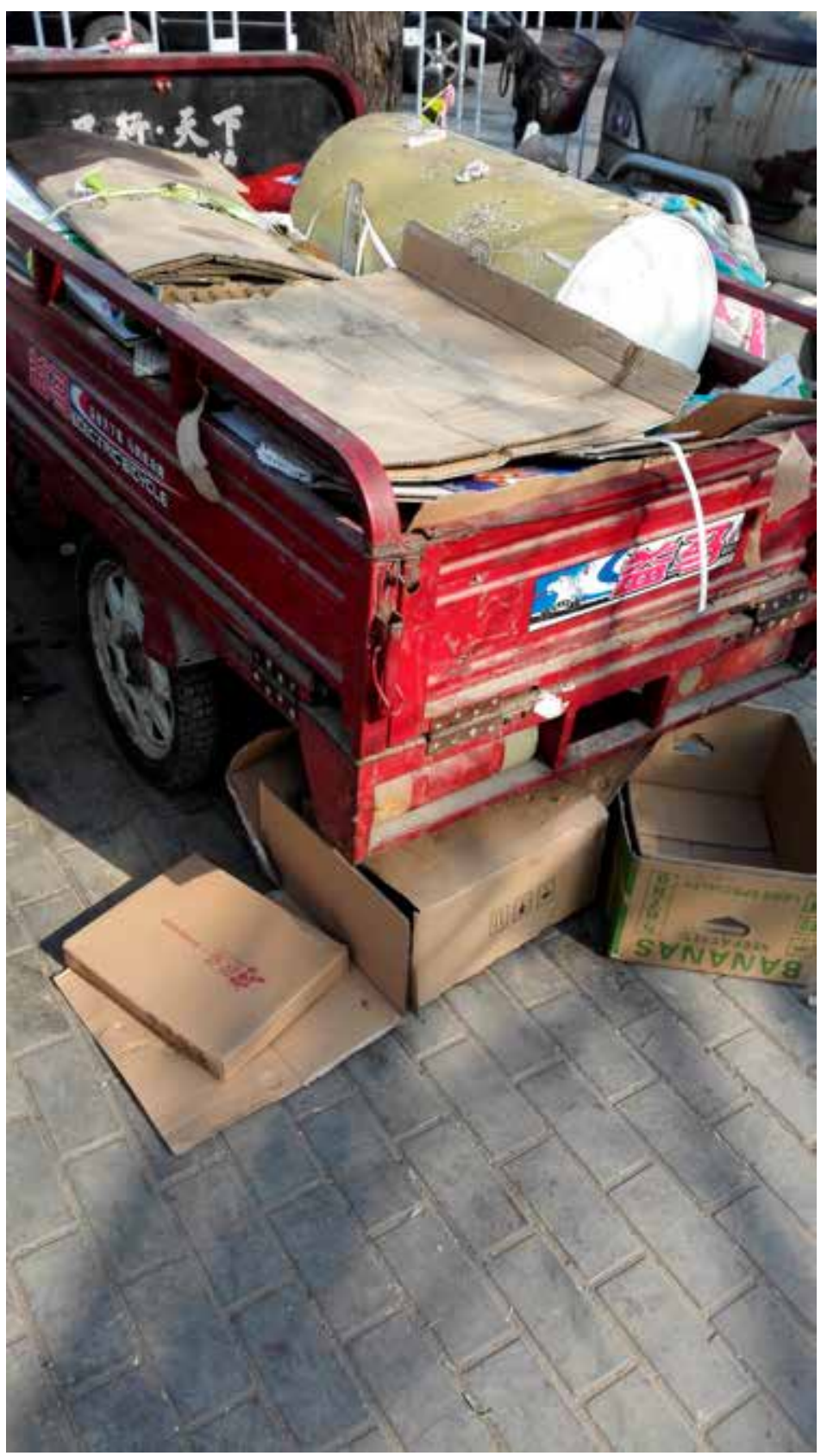

Author's photograph, 28 March 2017 
that the district is responsible for its ultimate disposal (Interview, 2017). The recyclables are carted off by (informal) tricycle operators. But aside from this seemingly organized system of waste disposal, with its deals and agreements that suggest a formal division of labour, there are other, smaller and independent operators at work as well. Some of them even have access to some sort of warehouses on the campus, keeping their loads in the often-disused air-raid shelters under the buildings. They carefully pre-sort the waste before they cart the recyclables away to the collecting station. I have not been able to establish how these more informal waste pickers are able to enter the closely guarded and patrolled university grounds, or how the contacts and contracts with the less informal ones are established or structured (Fieldnotes, 2017) (Illustration 4.2).

\section{Native-place ties}

Given the informality of the waste-picking sector, it is hard to estimate how many people are engaged in it in urban China. Some estimates mention the number five million, forming part of the 20 million people that are employed in one way or the other in the recycling industry nationwide (McKinsey \& Company and Ocean Conservancy, 2015; Inverardi-Ferri, 2017). But these estimates are hindered by the same problems that are encountered when using statistical data, as discussed in Chapter 1 (Linzner and Salhofer, 2014). Comparing various studies, Linzner and Salhofer have calculated that the number of people sorting waste in Beijing ranges anywhere between 130,000300,000 (2014: 903). A more recent estimate, from 2016, suggests that some 100,000 of them were left in 2014 (China Youth News, 2016). The influence and strength of the native-place ties are visible in the type of work they engage in and the locations they are active. The people who collect waste from Beijing's streets are predominantly from Sichuan Province. In 2016, there were at least 40,00o Sichuanese from the city of Bazhong (Dazhong District) alone working in Beijing. Most of the informal waste collectors I talked to were from Bazhong. The majority of the collection depots in Beijing that are still in operation are run by people hailing from a single district in Henan Province, i.e., Gushi district (China Youth News, 2016; Zhao, 2016; Tong and Tao, 2017; Interviews, 2017). ${ }^{12}$ In 2016, some 17,000 depot bosses from Henan were active in Beijing; the ones I encountered and spoke with were all proud natives of Gushi (Zhao, 2016; Interviews, 2017). People from Hebei Province 
have taken control of waste sorting and collecting in the area outside of the Fourth Ring Road. And migrants from Jiangsu Province have a monopoly over the illegal recycling of cooking oil, also called gutter oil (Zhao, 2016).

Henan is considered one of China's most densely populated provinces. Over the centuries, large numbers of migrants have left it, not only within China but moving out into the wider world as well. Gushi district is in the area that was severely affected by the famine of 1958-1960 that followed the Great Leap Forward campaign, which lead to more than 100,00o casualties in Gushi alone. Formerly an agricultural base, its labour force became redundant to a large extent after the Reform policies struck root in the early 1980 and decollectivization took place. This caused an exodus of labourers to provinces and cities such as Jiangsu, Guangzhou, Shanghai, and Beijing looking for non-agricultural jobs (Li, 2006). As with other former agricultural production areas that witnessed large numbers of their labour force move to urban areas, the remittances of these members of the floating population have contributed extensively to the present relative affluence of the district.

\section{The structure of the waste stream}

Roughly speaking, there are six layers of recyclers in Beijing, each successive layer adding value to the recyclable waste. These layers show a similarity with the make-up of the informal recycle systems that are in place elsewhere in the world (Ezeah, Fazakerley, and Roberts, 2013: 2512-2513) and consist of: 1 the scavengers, who freely pick up recyclables on the streets, in shopping malls, subway stations, residential communities, and landfills, dumps, or transfer stations. Alternatively, the free-moving scavenger is a waste picker who has come to an agreement with a residential community, restaurant, or other type of business to have exclusive access to the recyclable waste generated there. These agreements are often informal and can be quite costly, depending on the richness of the pickings. They can also be controlled by crime gangs that exchange access to junk for payment (Ensmenger, Goldstein, and Mack, 2005: 126; China Youth News, 2016). Other types of collaboration emerge between the drivers of municipal garbage disposal trucks and pickers, such as sharing valuable recyclables (Williams, 2014: 216; Kao and Lin, 2018).

2 the itinerant waste buyers, who collect recyclables door-to-door, paying for the items they pick up. They sell the waste to the medium or large redemption depots. Many of them use tricycles or bikes to transport what they have collected (Norcliffe, 2011) (Illustration 4.3). 
3 the small community waste-buying depots, operated by people who have paid a land usage fee to the community management committee in whose jurisdiction they operate. Through this, they have a permit from the local government to recycle. The small community waste-buying depots occupy some 5-10 square meters and do the waste collection in a community. These depots often resemble the portacabin structures that are used in the Hong Chao pilot project discussed in Chapter 3. Their operators stay in place and wait for people to bring them recyclables. In addition, they occasionally do some door-to-door recycling when people call them. Aside from these in-community depots, tricycle or truck-operating junk buyers are active curb-side, on street corners, and in small plots tucked away between the residential communities.

4 A variation on the previous layer is that of the recycling stand. These stands can be either of a periodic nature and independently run, or more regulated and contracted by the municipal government. Both operate on the sidewalks outside of communities. The periodic stands transport their materials to recycling markets or directly to the recycling plant, while the regulated stands sell directly to the recycling plants (Ensmenger, Goldstein, and Mack, 2005; Fieldnotes, 2015, 2017).

5 the medium/large redemption depots and recycling markets are where the collected recyclables from the community depots are brought together; the larger the depots, the further removed they are from the city centre. Over time, these depots have moved from the area between the Second and Third Ring Roads to between Fourth and Fifth Ring Roads to beyond the Fifth Ring Road. The operators of the trucks transporting the separated recyclables to ever-larger depots can be subjected to harassment and extortion from crime gangs (Ensmenger, Goldstein, and Mack, 2005: 126; Johnson, 2013a; China Youth News, 2016).

6 the recycling companies or factories are the final destination, where the waste ultimately is turned into new raw materials that can be reused. Plastics are processed in Wen'an, south of the city; Bao'an takes in the metal; paper ends up in Baoding; and glass is sent to Handan. Ideally, these companies and factories operate with pollution control equipment under the supervision of local governments, but this is not always the case (Ensmenger, Goldstein, and Mack, 2005: 121-124; Wilson, Velis, and Cheeseman, 2006; Linzner and Salhofer, 2014; Zhang and Wen, 2014: 993994; China Youth News, 2016; Steuer et al., 2017; Collective Responsibility, 2017). Under newly promulgated regulations to improve the air quality of Beijing, recycling factories in Handan, Baoding, and elsewhere have been ordered to cease operations, some only temporarily, some completely. 


\section{Illustration 4.3 A bicycle loaded with collected junk, Haidian District}

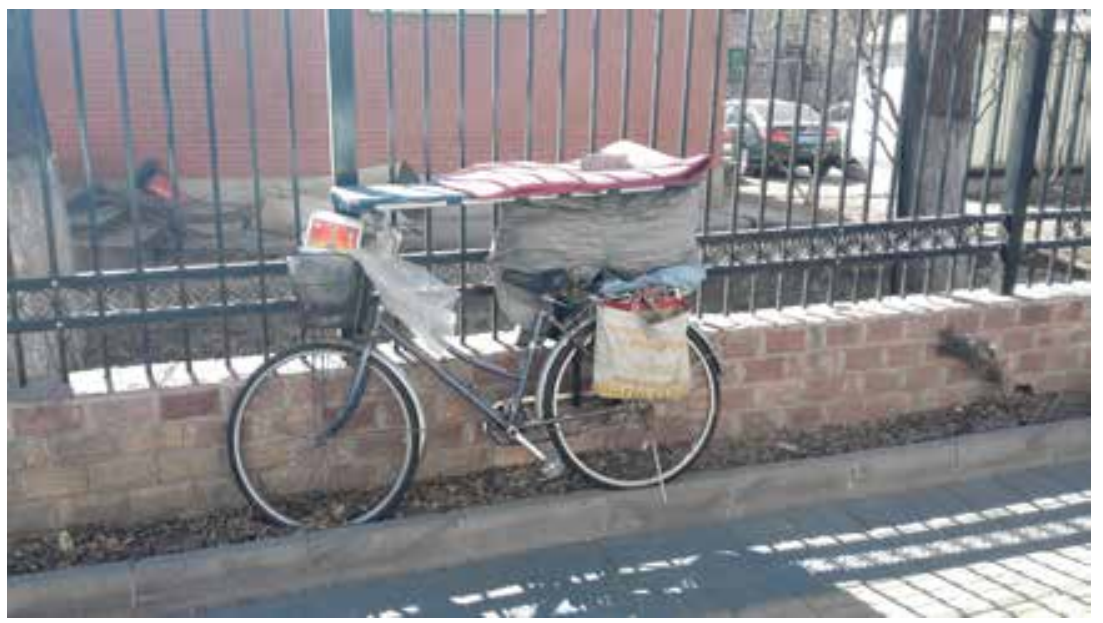

Author's photograph, 14 March 2017

The competition between informal waste pickers, augmented by a growing number of newcomers that continue to escape from the rural areas, and the expanding groups of original urban inhabitants who need scavenging to add to their income, is growing increasingly bitter. This latter group includes the old-age pensioners who can often been seen scavenging in an attempt to increase their pensions, particularly in parts of the city that are considered less well off (Liu and Wu, 2006; Goh, 2009; Griffiths, 2014; McKinsey \& Company and Ocean Conservancy, 2015). The frequent conflicts between informal waste collectors and the elderly can particularly be witnessed near subway stations, where many prospective metro users want to get rid of their (almost empty) PET bottles in anticipation of the security checks conducted before boarding. Other potential battlefields are crowded spots that promise lucrative hauls of recyclables. These destinations that draw large numbers of domestic and foreign visitors all year include the Happy Valley Water Park (Huanlegu), the Beijing Zoo, Yuanmingyuan and the Summer Palace (Yiheyuan), the Forbidden City, the various Olympic structures (Bird's Nest, Water Cube), etc. Less obvious destinations such as parks and even the neighbourhoods where the campuses of Peking and Tsinghua Universities are located can turn into potential places of contestation between waste collectors due to their large numbers of visitors (Fieldnotes 2015, 2017). 


\section{The Suzhi of waste pickers}

These out-of-town waste pickers are not looked upon kindly by either Beijing officials or residents. They engage in low-level work that city dwellers refuse to do and are considered to lack suzhi ('quality, culture'). This concept is discussed in more detail in Chapter 5 . Waste pickers and their work reflect badly on the ideas of modernity that the government entertains (Zhang, 2002; Inverardi-Ferri, 2017; Interviews, 2017). There is a growing resistance to informal trash collection in neighbourhoods where incomes and living standards are high. The higher the educational levels of the residents, and the higher the status potential of the residential community, the more outspoken the prejudice against migrants (Tse, 2016; Collective Responsibility, 2017). Waste workers have a bad reputation and are immediately associated with criminal behaviour by the 'fine' townspeople (Xu, 2008). They mess up the grounds of the community with their incessant digging through waste bins; they cheat when they buy valuable junk; and they cannot be trusted. There have been scores of reported cases of, as well as rumours about, migrant waste pickers who, being unable to find any valuable waste, have turned to stealing manhole covers, steel fences, transformers, and steel and copper cables - but that should not disqualify the whole contingent per se (Zhao, 2016). Chinese crime statistics report that a majority of police arrests concern migrants, and yet migrant workers are also more likely than residents to be the victims of crime (Sun et al., 2013). Aside from not being accepted in the urban environment for these reasons, administrative discrimination at all levels and popular distrust and suspicion have made it almost impossible to build a life in urban areas for those who were not born there. Having an urban hukou provides a passport to living in the city.

The Household Registration System regulations (hukou) that were introduced in $195^{8}$ basically divided the population into a very large rural and much smaller urban section, with the intention of keeping the rural inhabitants from moving to the cities. The main reason for the introduction of these rules was the nationwide famine that was threatening at the time. The rules were intended to protect the cities from being overwhelmed by starving peasants and to safeguard the meagre supplies of food that were available for city residents. These regulations brought to an end the freedom of internal migration and residence that had originally been written into the State Constitution that was in force at the time. The hukou system has seen some reforms and changes in the recent past, of which one, less strict enforcement, enables rural workers to move to the city temporarily. However, the restricting and restrictive rules built into the system basically 
continue to exclude migrants from full citizenship (Chan, 2009). For those who moved to urban areas after the reforms started, it remains extremely troublesome to find housing, rent a shop location, register vehicles, obtain a local cell phone number, register a business, get a loan, etc. The hukou system continues to deny migrant workers a number of basic entitlements that urban residents can lay claim to, thus making the managing of family life, i.e., renting housing and sending children to school, equally cumbersome. Even though further reform of the hukou system has been in the works for years, little progress has been made. Despite their essential role in the city, urban residents and officials continue to look down on migrants, seeing them as population pollution (Goldstein, 2006; Zhang and Li, 2016; Goldstein, 2017: 178).

\section{Urban villages}

As a result, migrant workers have been forced to converge on the outskirts of the city, to the hybrid areas where town and country merge, a space also known by the term desakota (Béja et al., 1999a: 29; Davis, 20o6; Yates, 2011). Native-place ties and chain migration processes have resulted in the concentration of people moving from the same districts, towns, and provinces in the same settlements, hence the appearance of migrant enclaves within Beijing. In 2008, 876 of these were identified but not included in the urban statistics (Zheng et al., 2009: 428). Similar migrant enclaves emerged around other tier-one, -two and -three urban areas as well. The more famous ones in Beijing - famous due to the broad interest that they attracted over the years from both Chinese and Western researchers - were known as 'Henan Village', formerly located in a part of Haidian District that still was seen as a suburban area in the 1990s, and 'Zhejiang Village' in Fengtai District, which housed some 100,000 migrant entrepreneurs from Wenzhou and hired-wage workers from other regions. Some other enclaves gained fame for a while as well. What distinguishes these enclaves is that they were all named after the location that the majority of their inhabitants hailed from (Béja et al., 1999a; Zhang, 2002: 317). These configurations, villages-in-cities or 'urban villages', also retained strong village features (Zheng et al., 2009; Shin and Li, 2013; Zhao and Zhang, forthcoming). The migrant centres evolved into small worlds unto their own: they had and have their own supermarkets, eateries, laundry shops, vendors, and other stores, some run by self-employed migrants, that supply services and cater to tastes that make their inhabitants feel like they are at home though abroad $(\mathrm{Xu}, 2008$; Zheng 
et al., 2009; Loyalka, 2012). Each of the enclaves rendered different services to Beijing's economy and society:Henan Village provided labour and served as a market for garbage collection, while the people living in Zhejiang village mainly worked in the garment industry. At one point, Zhejiang village even acquired a monopoly in Beijing and North-eastern China over the clothing produced there, which was marketed as original Zhejiang Province items (Béja et al., 1999a; Zhang, 2002: 317; Ou, 2011).

Pushed out of the city and finding it nearly impossible to find affordable housing, migrant workers were often forced to rent accommodations from local peasants who used to work the soil. In the period 2005-2017, I have seen the area known as Sijiqing, located south of the Summer Palace and between the West North Fourth and Fifth Ring Roads, evolve in this process (Fieldnotes 2005, 2007, 2008, 2010, 2012, 2015, 2017; Zheng et al., 2009). Sijiqing used to be an agricultural base of production, with rural villages, farmland, orchards and tree nurseries, and only a few small migrant communities. Over the years, habitation increased and residential communities for Beijingers emerged; car dealerships sprung up; both shady and more respectable karaoke bars set up shop; informal night markets appeared, attracting thousands; and the number and size of the migrant communities congregated there grew. Over time, the area slowly but surely gentrified, connecting it with the network of public transport, forcing out the establishments and inhabitants that were considered less savoury and replacing them with more appropriate people and businesses, including hotels and golf courses. By 2017, the area has become a fully integrated part of the larger district, particularly the area bordering both sides of the Fourth Ring Road. The migrant population that initially found ways to establish itself there has been forced further west and north beyond the Fifth Ring Road, learning about alternative 'cheap rental through word of mouth, via friends or relatives, or by reading casual advertisements in the village' (Ou, 2011; Liu, Wong, and Liu, 2012: 1233).

While most agricultural workers in suburban areas lost their rights to toil the land in the process of Beijing's outward movement of urbanization, they discovered a way to earn some (extra) income by renting out rooms in structures built on the parcels of land reserved for housing to migrants at affordable prices (Liu, Wong, and Liu, 2012; Zheng et al., 2009:426). Many came up with strategies to expand the rental possibilities of their homes, such as building floors on top of existing dwellings, but this seriously decreased the safety of those renting these rooms. Others built housing compounds (dazayuan 'mixed buildings') (Xu, 2008; Zheng et al., 2009; Ou, 2011; Shin and $\mathrm{Li}, 2013$ ). Yet even communities such as these were demolished in the 
end. The famous Zhejiang Village, for example, was finally levelled in 2006 to make room for construction work related to the 2008 Beijing Olympic Games (Xu, 2008: 648; Shin and Li, 2013); the people working there had, in the meantime, spread out to almost every city in China (Zhang, 2002: 317). The last inhabitants of Henan Village were still working in the recycling trade in 2017, in a few tiny corners that were left of the original enclave. They too had been given notice that they would have to move elsewhere before the end of the year, due to the construction of the residential quarters for Tsinghua University staff that was already encroaching on their work space (Fieldnotes, 2017; Interviews, 2017).

\section{Hongfu Yuan}

The destruction and ultimate disappearance of these migrant communities is not predestined. Zhao and Zhang (forthcoming) have traced the development of the northern Beijing village of Zhenggezhuang, located between the Fifth and Sixth Ring Roads. They convincingly argue how informal and even partly illegal communities such as these can evolve into 'respectable' gated communities, as in the case of Hongfu Yuan, which currently accommodates migrant residents, college students (from the branch campuses of the Beijing University of Posts and Communication (BUPC) and the Central Academy of Drama (CAD)) and 2456 indigenous villagers. The gated community is the result of the transfer and pooling of the land-use rights of the original villagers into the Hongfu Group in 1999. This group is responsible for the governance of the community and administering its further development and diversification, which includes the construction of a tourist resort (Wendu Water City) with hotels, a golf course, and a shopping mall. Hongfu Group has been able to entice the Beijing Bus Company to provide bus services to the community, including one rapid transit bus line, linking it with the city proper.

\section{Lajicun ('Junk villages')}

Zhenggezhuang is an obvious success story for the informal communities that are emerging around the city, and about the ways and strategies for those working in the informal economy to carve out a space (Liu, Wong, and Liu, 2012). It is not representative of the many other suburban population centres where economic processes have forced the scrap collectors and 
their recycling stations over the years. They have been pushed out by the same housing estates and shopping arcades where the recyclables that they collect, separate, and sell are produced in ever-increasing amounts. The scrap collectors and recyclers have taken refuge in 'junk villages', which take their name from the junk and recyclables that are concentrated there and the scrap markets that they organize. The 'junk villages' often operate the legal, semi-legal, and illegal garbage dumps in their vicinity as enterprises (Kao and Lin, 2018). These villages surround the urban area of Beijing like a virtual Ring Road (Wang, 2011). The process of forcing the activity of recycling ever further out of the built-up areas has made the process of carting away garbage increasingly time- and energy consuming, irrational, and expensive.

While dealing with domestically produced garbage has thus been made ever more difficult, the situation has been compounded by another factor that imperils the functioning of these 'junk villages'. It also serves as an illustration of the way in which informal Beijing migrant workers have been made part of the global nature of the junk, scrap, and recycling enterprise (Medina, 2011). Located as they are near the garbage dumps that they operate as enterprises, for years the villagers have been processing the garbage of the world that China has both produced itself and imported from elsewhere (Goldstein, 2006). According to government figures, China imported 49.6 million metrics ton of waste in 2015 (Agence France Press, 2018). As Adam Minter (2013a: 85-88, 2013b, 2015) has explained, for an extended period of time the shipping containers that carried export products from China to consumers worldwide also brought back the garbage produced by those consumers, for a reduced rate. The shipping companies could not allow containers to return empty to China. The export of finished products and the import of junk created an almost perfect loop. The extraction of muchneeded raw materials and recyclables from the waste produced elsewhere has thus allowed the Chinese industrial export machine to attain the level it has today, churning out more and more products that are consumed globally, and in the process producing more waste that has no place to go. By importing and using the refuse of the world, China has been able to preserve large amounts of the nation's virgin resources, energy, etc. In a perverse way, this process has therefore contributed to an improvement of the environment. In the summer of 2017, however, the CCP Central Committee and State Council adopted the '2018-2020 Action Plan for Full Implementation of the "Implementation Plan for Banning Foreign Wastes and Advancing the Institutional Reforms on the Management over Importation of Solid Wastes"', making it clear that it was no longer interested in recycling other nations' garbage. The ban on the import of foreign waste, which took effect on 
1 January 2018, is to be fully implemented by 2020 (State Council, 2017; MEE, 2018). This decision was not only based on the fact that the country produced enough garbage of its own; it was also seen as promoting the development of the circular economy. The Plan, moreover, gives opportunities to the governments at various levels to further regulate, and make healthier, the domestic recycling sector, phase out informal waste pickers, etc. The ban has caused a huge headache for the international garbage-producing and -recycling industry (Agence France Press, 2018).

\section{Closing down the waste villages}

A number of the waste villages surrounding Beijing have become important sites for research by Western academics. Whereas in the $1990 \mathrm{~s}$ these researchers studied the emerging entrepreneurship amongst the migrant population in Henan Village and Zhejiang Village, in the first two decades of the millennium their attention has shifted elsewhere, focusing on marginalized people leading precarious existences by sorting through waste. Many of these villages remain nameless, but the villages of Dongxiaokou in Changping District (Zhao, 2016; Steuer et al., 2017; Goldstein, 2017; Inverardi-Ferri, 2017), Huangcunzhen in Daxing District (Steuer et al., 2017), Lengshui (Wu and Zhang, 2016) and Picun ('Leather Village') in Chaoyang District (Huang, 2015), and others have become household names in the field. Although the activities of the villagers and their living conditions have been used by municipal departments to further their own agendas, such as the promotion of incineration, they continue to be seen as unwanted side effects of modernization that the city wants to get rid of. Liu, Wong, and Liu, for example, refer to the 2010 city-wide adoption of new residency control measures by Beijing Municipality as embodied in the 'Shunyi Model' and the 'Daxing Model' (2013: 366-369). Starting in 2000, these two districts focused on building higher-end industries that require a higher skilled workforce, who in turn demand higher-end housing. This approach has slowed down the increase of low-wage migrants moving into the districts and has gentrified the areas, as illustrated by the example of Zhenggezhuang.

In late 2017, after a fire broke out in one of the many illegal structures in the Xinjiancun section of Dongxiaokou, the Beijing municipal government and other official departments started a number of concerted campaigns to drive out migrant workers, now termed the 'low-end population', and force them to return to the places they hail from. This can be seen as the 
final act in a long series of attempts to regulate these and other waste villages (Chen, 2014; Battaglia, 2017). According to Michelle Yates, this is the next stage of waste management and disposal, which 'recently has taken the form of "eviscerating urbanization", i.e., the cleaning up and removal (management and disposal) of slums and slum residents' (2011: 1687). What does this mean for the garbage collection, retrieval, and recycling sector? Or, to put it differently, who will take care of urban garbage now?

\section{Types of $\mathrm{O}_{2} \mathrm{O}$ employments}

This is the point where the activities of the $\mathrm{O}_{2} \mathrm{O}$ companies introduced in Chapter 2 come in. They are well-organized, boast of a well-behaved workforce in designated uniforms, and promise secondary pollution-free waste disposal. In short, they are just the types of waste collectors that the government would like to have. But is this work attractive or available to the informal waste pickers? What does it mean for them to become an employee of such a company, someone hired to pick up the recyclables that have been reported by citizens using dedicated apps on their smartphones? And what does it take to become such an employee? My attempts to have such questions answered by the $\mathrm{O}_{2} \mathrm{O}$ companies themselves did not lead to any results. Instead, I engaged in extended research on the internet pages of three of the companies operating in Beijing that listed vacancies. This has resulted in the following information concerning the types of employees they were looking for at the time. It also sheds light on the diversity and breadth of the activities that $\mathrm{O}_{2} \mathrm{O}$ companies are engaged in or planning to branch out into.

\section{Taoqibao}

Taoqibao only has openings for 'recyclers'. The Taoqibao website ${ }^{13}$ defines what it expects of 'recyclers', as it calls its potential employees. They must be aged between 18-35 years, and they should have completed high school, secondary school, vocational high, technical or higher, but college education is preferred. Their facial features should be correct: they should have a good image, a smooth expression, and be clear thinking. They should be able to work hard, have a strong sense of professionalism and responsibility, and be interested in the company's long-term development. The website does not explain what working as a 'recycler' means. It is not clear what 
showing interest in the long-term development of the company means for the individual applicant. But the requirements show that migrant workers are certainly not the most likely group of people to be hired for this position.

In return, the employee earns a fixed monthly salary of 2200 yuan; this can increase through commissioned (piece-rate) wages to an average income of 4000-7000 yuan per month. The company offers social insurance covering a retirement pension, medical insurance, unemployment insurance, work injury insurance, and maternity insurance. It also provides employees with birthday presents and a variety of holiday gifts. Work clothes are also provided free of charge throughout the year, but the website does not indicate what these include. The company organizes a variety of staff activities, ostensibly to create a true company spirit. Aside from full-time employees, the company is also interested in contracting freelancers, people who want to make money in their spare time. According to the website, the earning opportunities are almost similar to those of white-collar workers.

\section{Zai Shenghuo}

New Living (Zai Shenghuo) is looking for the largest number of employees, which is in line with their plans to expand their activities to other fields, as discussed earlier. Their recruitment page ${ }^{14}$ lists the following vacancies. All job descriptions include the provision that wages are paid on the 1oth of each month, and that no money will be withheld. The need to specifically spell out this provision indicates that some companies are slow in paying, or are holding back part of the wages for whatever reason.

- App promoters, i.e., persons who urge others to download and use the app. For this job, people between 18 and 28 of both genders can apply; the household registration status of the applicants is not relevant. There is no fixed salary mentioned, although the income range is quoted at 400012,000 yuan per month, based on piece work rates. There is no indication how these rates are calculated. The job is on the basis of a contract and comes with insurance. The company promises 'career development space'.

- Couriers (tricycle operators), who are responsible for daily delivery services and maintenance jobs. They should be 18-35 years old; household registration is irrelevant; and education level should be at least junior high school. Wages are based on a monthly salary (level not specified), augmented with a performance salary, competitive bonuses, and other components. The average income can reach 5000-800o yuan per month but is dependent on 
piece-work rates. There is no cap on income. Pre-job training is provided by the company, which also offers staff career-development space. Work is done on the basis of a formal labour contract with insurance. Free work clothing is provided, and implements/tools used on the job are provided free of charge and deposit. The company frequently organizes recruitment drives for promotion, training, and internships.

- Mobile phone detection engineers (home), who test mobile phones, tablets, notebooks, cameras, and other electronic equipment. The company is looking for people with a college degree or higher, under 30 years of age; they should be handsome, healthy, and hard-working, have a strong sense of responsibility, a good team spirit, master standard Mandarin Chinese, and have good communication skills. Pre-job training is provided by the company, so previous knowledge of the technologies is not required. The company offers a staff career-development space. Work is done on the basis of a formal labour contract and includes insurance. No salary specification is given. Note that the requirement to communicate in standard Chinese has the potential of barring migrant workers from these jobs.

- Air conditioning replacers. They should be 20-35 years old and have at least one year of experience working in the air conditioning business. The monthly salary is based on a basic salary plus commission, totalling 4500 yuan per month, dependent on piece-work rates. The company offers staff career-development space. Work is done on the basis of a formal labour contract and includes insurance.

- Sorters, who sort garbage at collection stations. The company looks for persons 18-40 years old, hard-working, with a strong sense of team spirit, and expects long-term commitment. The monthly salary is 4000-60oo yuan, but this is without a contract or insurance.

- Truck drivers, who should be 25-40 years old, hold a B2 driver's license (freight certificate) or higher, and have more than two years of actual driving experience. They must be familiar with the local road conditions, have a good driving record without major accidents and traffic violations, and have a strong sense of security. The salary amounts to 4000-8000 yuan per month, on the basis of a formal labour contract including insurance.

- Warehouse managers should have an education record of secondary school or higher and be aged 20-35 years; they should have more than one year of relevant work experience. The salary is 4000-6ooo yuan per month on the basis of a formal labour contract including insurance. 
On top of that, the company also provides free staff quarters on the premises, with a kitchen and independent bathroom.

\section{Incom}

Incom advertises only a few job openings on its website, ${ }^{15}$ but none concerning the collection of recyclables. They are more like back-office occupations that deal with tasks related to running the company itself. This is remarkable, as Incom was the first company to boast about hiring informal waste pickers to stop the competition over recyclables. They have declared that they have 300 garbage collectors under their employment, but it remains unclear how they were recruited and hired. The job openings they do offer on the website range from technical service engineer, Image Recognition Senior R \& D engineer, and Senior Electronic $R$ \& D engineer, to environmental Research Fellow. All these functions typically demand higher education degrees, ranging from BA to MSc levels; for none of these employment opportunities is an indication of the salary range given.

After comparing the vacancies that the three $\mathrm{O}_{2} \mathrm{O}$ companies advertised, one must conclude that the informal waste collectors, who usually hail from the cohorts of migrant workers, do not seem to fit the demands. The recruiters are looking for human resources that have an urban registration, finished school education at the secondary, vocational, or higher level, speak fluent standard Chinese, look pleasant, and so on.

\section{The appeal of working for an $\mathrm{O}_{2} \mathrm{O}$ company}

The $\mathrm{O}_{2} \mathrm{O}$ companies have not changed the status of the waste pickers. The latter have not become stakeholders in the process of recycling, a development that some consider a necessary step for their acceptance and inclusion (Tong and Tao, 2016; Goldstein, 2017). Chen Liwen, formerly attached to the Green Beagle environmental NGO, has vividly recorded the endless toils of Mr. and Mrs. Ma in her 2012 video 'A Beijing Recycler's Life' (Chen, 2012). Would the Mas consider joining an $\mathrm{O}_{2} \mathrm{O}$ outfit? Would they see it as an option to gain social capital (Prasad et al., 2012)? Would it change their personal connections with residents, which have been witnessed and reported on so often (Prasad et al., 2012; Minter, 2013a; 
$\mathrm{Wu}$ and Zhang, 2016)? Are the garbage pickers employed by the $\mathrm{O}_{2} \mathrm{O}$ companies competing with the 'freelancers' who are still very much active? Have there been any 'waste wars' between pickers from different $\mathrm{O}_{2} \mathrm{O}$ companies? And where do the old-age pensioners who pick garbage fit in this scheme? Can they join an $\mathrm{O}_{2} \mathrm{O}$ company? Are they willing to do so, and are there examples, other than the ones suggested by Chinese media reports (Zheng J., 2017)?

When interviewing waste pickers, collection station bosses and workers, and regular sanitation workers about these topics, they were initially amused by my questions and then invariably scoffed at my suggestion that they join an $\mathrm{O}_{2} \mathrm{O}$ company. Was their lack of an urban registration, education, and professional ability not the reason why they ended up in the recycling trade in the first place? - they argued. And did they, who had acquired their knowledge in practice, really need to be trained to do a job that required no training? - they continued. And why would they need to raise their level of providing service to their customers? None of them considered working for an $\mathrm{O}_{2} \mathrm{O}$ company to be a serious option. They did not recollect encountering any $\mathrm{O}_{2} \mathrm{O}$ workers and thus they were not considered competitors. They also saw the work and income potential of working for an $\mathrm{O}_{2} \mathrm{O}$ company as unfavourable, mentioning various reasons. First of all, both the pickers and the station bosses and workers considered the pay much too low, uttering lines like 'If you are willing to work hard, the [independent] income is much higher', 'This is only for fancy kids who do not know what hard work is', and 'They are only interested in high-end waste'. Only Mr. Li, a 53-year-old waste picker from Bazhong, seemed to like the idea of working for a company, but he assumed that it meant earning less and therefore decided that it was not worth his while. While agreeing that the informality of their work could mean that they earned less on some days, most pickers were convinced that they could do much better than the 2000 yuan-a-month that most of the lower-level $\mathrm{O}_{2} \mathrm{O}$ jobs offered. Indeed, the correlation between hard work and high income was mentioned most frequently, and with considerable pride. Some bosses let on that they had been approached by $\mathrm{O}_{2} \mathrm{O}$ companies but had turned down their offer of a more formal type of cooperation. The bosses said that the 3000-4000 yuan the companies had offered them did not compare to the amount of money they could earn themselves in a day by depending on their own labour power. Mr. Wang, a 40-year-old boss from Gushi, Henan, told me he sometimes bought some of the junk that the $\mathrm{O}_{2} \mathrm{O}$ companies offered him, but he only did so when he could get it for a good price. In other words, $\mathrm{O}_{2} \mathrm{O}$ companies were just business relations 
Illustration 4.4 Discarded bicycles awaiting transport at a Haidian District scrap collection point

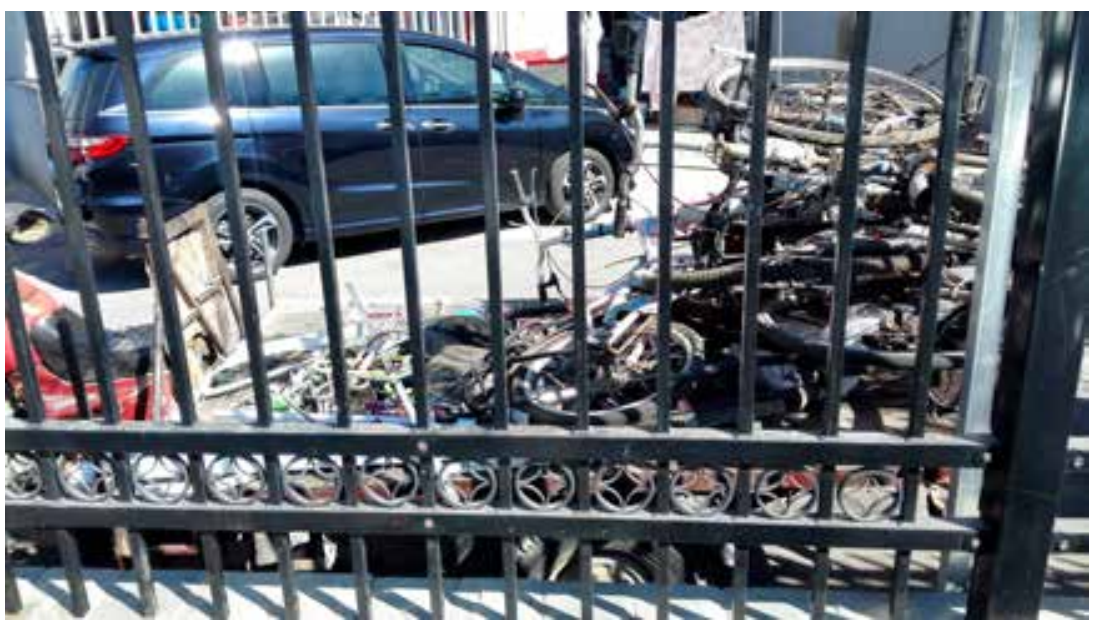

Author's photograph, 14 March 2017

like any other, nothing special. He did not see his dealings with them as a formal type of employment, but just ordinary business (Interviews, 2017) (Illustration 4.4).

Neither pickers nor bosses had heard about the smartphone apps that the $\mathrm{O}_{2} \mathrm{O}$ companies had developed, and they wondered what they were. When I showed them how some of them, like Bangdaojia and Taoqibao, worked, they were not impressed. The pickers did not like the idea that they could be summoned to a residence to pick up waste. This actually contradicted the stories reported in a number of Chinese media articles that referred to the convenience the apps provided for the pickers (Zhang, 2016; Zheng J., 2017). A few of the bosses mentioned that sometimes long-term clients with which they had built profitable relations, like companies or restaurants, would contact them in the old-fashioned way, giving them a phone call when they had junk for sale. They usually decided on the spot, depending on the price they had to pay for such offers, and could not be bothered by the idea of set prices. By and large, my sources sounded suspicious of the apps. They were convinced that these were just tricks engineered by the $\mathrm{O}_{2} \mathrm{O}$ companies to get government subsidies; using apps would not change anything in the business of collecting and selling waste (Interviews, 2017).

Then there was also the issue of the informality of the work they currently did. As individual workers, they had more freedom and rights to decide the prices they bought and sold for, the workload and time they wanted 
to invest - even though the $\mathrm{O}_{2} \mathrm{O}$ job descriptions did suggest piece rate payment (Interviews, 2017). None of my sources indicated interest in joining something like an actual company. 'My income solely depends upon myself. If I work today, I get paid', was the type of answer they regularly gave. The possibility that joining an $\mathrm{O}_{2} \mathrm{O}$ company would provide their work with some protection from external pressures, like governments or the feared and hated city management officers (chengguan), did not occur to them. In fact, the waste pickers did not mention feeling any pressure at all from these corners. Some of the bosses said that these types of pressure were precisely the sort of grief they had to deal with, but it all came with the territory. The trouble of finding new vacant lots for their separation and collection activities gave them the biggest headache. They were under constant pressure to move further out of the city, as their collection points were taken over time and again. The prospect of wearing a company uniform did not appeal at all and even seemed to embarrass my sources a little, although they were partial to the idea of getting some sort of work clothes for free. They were not at all attracted by the promise of social insurance that some of the $\mathrm{O}_{2} \mathrm{O}$ contracts offered, as they were convinced that the premiums would be taken out of the wages. The only thing they liked about the $\mathrm{O}_{2} \mathrm{O}$ employment, particularly in the opinion of the waste pickers, was the chance to get free tools, like a cart. In 2001, a tricycle cost 200 yuan to use; by 2015 , that had gone up to 2000 yuan, and in 2017 , the costs had gone up again (Goldstein, 2006; Hunwick, 2015; Interviews, 2017).

As for gaining status and being more accepted by the native Beijingers by becoming a regular employee, they were not convinced that joining an $\mathrm{O}_{2} \mathrm{O}$ company was the right way to accomplish that. After all, they 'had no culture', they lacked suzhi. They wondered whether they actually wanted to do all of this in return for gaining acceptance; rather, they indicated that the respect they had or could gain in their own communities back home mattered more to them than acceptance in Beijing. All of them were positive that joining an $\mathrm{O}_{2} \mathrm{O}$ company would help them cut back on the expenses of acquiring the various permits that were required for their work, but they were also certain that going the $\mathrm{O}_{2} \mathrm{O}$ way would not help them get access to an urban registration (Interviews, 2017).

The attitudes of the regular sanitation workers differed from those of the informal waste workers in many respects. Most of the regular workers were born and bred Beijingers, so the prospect of joining an $\mathrm{O}_{2} \mathrm{O}$-company to get an urban hukou had no appeal for them whatsoever. Moreover, they already worked for the sanitation departments of the municipal or district governments, or for residential committees. Although they were engaged in 
lowly work, it still afforded them face and respect, as they held an official position of a sort. All of the sanitation workers I interviewed were proud of their work and their contributions to society. They wore their uniforms with pride, as they distinguished them from others and gave them a formal position in the wider scheme of urban society. As they drove their garbage trucks or tricycles to collect junk, all provided by their municipal employers, the idea of having free tools of the trade at their disposal had no appeal at all (Interviews, 2017).

\section{Informal versus $\mathrm{O}_{2} \mathrm{O}$ waste picking}

One can say that the $\mathrm{O}_{2} \mathrm{O}$ companies' claims that employing waste pickers had a positive effect on the amount of junk they were able to gather seem dubious. Not one single $\mathrm{O}_{2} \mathrm{O}$-employed waste picker, and only one company-designated vehicle, was encountered during my three months of research. Factoring in the fact that the $\mathrm{O}_{2} \mathrm{O}$ companies' base of activities was in other parts of the city, it still came as a surprise that the informal waste pickers and bosses were mostly unfamiliar with their existence and work. Although an informal information network among those employed in waste picking exists, it seems that $\mathrm{O}_{2} \mathrm{O}$ companies and their operations did not merit a mention there.

Likewise, working for an $\mathrm{O}_{2} \mathrm{O}$ company clearly held no appeal for the pool of labour power that the $\mathrm{O}_{2} \mathrm{Os}$ would like to tap. Waste pickers and bosses consciously favoured the informal aspects of their work, the ability to earn more if one worked hard, and not having to tolerate some supervisor looking on. From the perspective of the people working the waste, $\mathrm{O}_{2} \mathrm{O}$ companies were irrelevant. 
